\title{
ЦИФРОВИЗАЦИЯ ШКОЛЫ: ШКОЛЬНАЯ ЖИЗНЬ В УСЛОВИЯХ МОДЕРНИЗАЦИИ
}

\author{
Бобкова И.А.
}

Россия начала активное движение в направлении полноценной иџифровой экономики, интегрированной в мировое хозяйство. Этот проиесс невозможен без вовлечения в него образовательных учреждений (ОУ). Электронная (цифровая) школа включает техническую инфраструктуру и специиализированное программное обеспечение, внедрение ИКТ в образование, подготовку электронных учебников. В работе проанализированы различные формы вовлечения ОУ в глобальное циирровое преобразование российской школь.

DOI: $10.20537 /$ mce2019econ09

Введение. Московская электронная школа (МЭШ) - проект Министерства образования и науки РФ по внедрению высоких технологий в школьное обучение. В рамках этого проекта все школы Москвы были подключены к системе «Электронного дневника» (Электронный журнал и дневник - ЭЖД), в части школ в классах установлены интерактивные (цифровые) доски с широким функционалом. Также создана электронная библиотека на портале mos.ru, в которой можно найти большинство необходимых для обучения учебников [1].

Но так ли полезно это нововведение, как кажется при первом взгляде? Оправдаются ли затраты на закупку нового оборудования, повысит ли оно успеваемость детей, сэкономит ли время и силы учащихся и преподавателей?

Отметим ряд недостатков, выявленных в конкретной школе уже при поверхностном взгляде на эту проблему.

1) ЭЖД периодически «зависает», изменение и выставление оценок затруднено, домашнюю работу на каникулы учителя не могут выдать из-за технических особенностей системы, доступность прямой связи «учитель - заболевший ученик» чисто гипотетическая. 
2) Сразу же после начала учебного года с интерактивными досками в кабинетах возникла проблема: учителя не имели достаточного опыта для нормальной работы, дети не могли приспособиться к новой системе.

3) Школьники зачастую вместо чтения учебников в электронной библиотеке на своих телефонах отвлекаются, играют в игры, сидят в социальных сетях или занимаются посторонними делами, что, естественно, негативно сказывается на образовательном процессе.

Целью исследования стало выяснение того, окупает ли польза от МЭШ затраты на ее введение, нужно ли принудительно внедрять технологические новшества в процесс обучения или же необходимо поставить этот вопрос перед учителями, учениками и их родителями. Но, так как система электронного образования уже начала вводиться в школах Москвы, более актуальным может стать вопрос о необходимости внесения изменений в систему МЭШ, чтобы процесс обучения и внедрения новых технологий проходил более комфортно, не вызывая существенных трудностей у учителей и учеников.

Цифровизация школы как приоритетное направление модернизации образования. Процесс реформирования экономических институтов с точки зрения перевода их в цифровое пространство становится все более активным, опираясь на Постановление Правительства РФ № 1632-р об утверждении программы «Цифровая экономика Российской Федерации» от 28.07.2017 [2], ставшей частью «Стратегии научно-технологического развития РФ». Система образования - одно из наиболее приоритетных направлений в этом процессе, так как фундаментальная перестройка экономики невозможна без квалифицированно подготовленных кадров.

Модернизация общего образования в той или иной степени затрагивает все школы г. Москвы. Школы массово обеспечиваются цифровыми (электронными) досками и электронными учебниками [3]. С 2015 г. в России можно издавать только учебники, для которых есть электронная версия. Однако, переход на цифровое образование достаточно дорогое дело, например, в Великобритании это соответствует 300-360 тыс. руб. на 1 ученика. Пока нет точных расчетов требуемых средств для российских учащихся. Настораживает и то, что лучшее оборудование получают школы из первых строчек рейтинга, тем самым дополнительно увеличивая расслоение учащихся по уровню образования.

Первым шагом по пути цифровизации школы стало введение электронных журналов и дневников (ЭЖД). В московских школах система «Электронный дневник» действует с 2010 г. Сначала ЭЖД реали- 
зовывались на базе конкретных школ. Сервер находился у системного администратора школы. Затем произошло объединение ЭЖД на единой (московской) платформе. Несмотря на ограниченный функционал, первые ЭЖД практически «не висли», могли быть скорректированы под нужды конкретной школы, учителя имели возможность исправить вкравшиеся при вводе информации ошибки, исправить плохую оценку после ее исправления учеником. «Случайный прокол» не мог повлиять на успеваемость ученика. В целом, система была адресная и в большей степени соответствовала менталитету российских учителей и учеников. Затем была создана единая система «МЭШ», в рамках которой сейчас функционируют электронные дневники. Сейчас в эту систему входят:

- цифровые доски (ЦД) - интерактивные многофункциональные панели, размещающиеся в классах и призванные заменить обычные меловые доски и экраны, поддерживающие выход в Интернет, стандартный пакет Microsoft Office, использующиеся как экран или доска;

- электронные учебники - специальные устройства, заменяющие обычные бумажные учебники или же особое программное обеспечение, использующееся вместо «стандартных» учебников;

- электронная библиотека МЭШ - ресурс, открывающий доступ к большинству использующихся в школах учебников. Формально все учебные пособия, использующиеся в школах, должны находиться в электронной библиотеке, однако в реальности это не так;

- готовые интерактивные сценарии уроков, которые могут использовать преподаватели для более эффективной организации учебного процесса;

- электронный дневник и журнал - система прямой связи учителя с учеником, выставления оценок, проверки и выдачи домашних заданий, заменяющая бумажные дневники и журналы,

В общей сложности на цифровизацию московских школ в 2018 г. было выделено 456 млрд руб., из городского бюджета потрачено 266 млрд [3]. На программу «Столичное образование» (Департамент образования и науки) в 2019 г. выделено 296.8 млрд. руб. В рамках этой программы запланированы ежемесячные надбавки в размере 10 тыс. руб. для учителей, активно участвующих в разработке сценариев для МЭШ [4]. Сейчас в открытом доступе представлено около 30 тыс. электронных сценариев уроков. Вообще, по словам Дениса Заики [5], «наполнение МЭШ — заслуга московских учителей. Именно благодаря их 
работе МЭШ признается ...наиболее перспективно развивающейся цифровой системой в образовании по сравнению с ведущими мегаполисами мира». Московские учителя до 2017 г. делали это бесплатно. В 2019 г. их решили поддержать крупными грантами (722 человека из 314 школ по итогам 2018 г., до 150 тыс. руб.) и ежемесячными выплатами [6].

Социологическое обследование учащихся и учителей. Для прояснения вопроса о пользе от внедрения МЭШ в процесс обучения был проведен социологический опрос учащихся из физико-математического лицея (из «Топ-25» школ г. Москвы). Опрос проводился в декабре 2018 г. при содействии учеников школы А. Бобкова и К. Белякова, которым автор выражает свою благодарность.

Характеристика респондентов: 458 человек, в том числе женщин 184, мужчин - 274. Распределение по классам: 5-7 классы - 138 (54 и 84 соответственно); 8-9 классы - 79 (33 и 46); 10-11 классы — 240 (96 и 144).

Электронный дневник. Прежде всего, мы проанализировали мнение учеников об электронных дневниках (ЭЖД), которые функционируют в московских школах уже несколько лет и хорошо всем знакомы. У каждого ученика, учителя, родителя уже сложилось об ЭЖД свое определенное мнение. Ученикам задали всего два вопроса: «Какие плюсы и минусы Вы видите в замене бумажного дневника на электронный?».

Результаты обследования. Главные плюсы ребята увидели в уменьшении веса портфеля и в возможности сразу видеть средний балл по предмету. Средний балл с введением электронной системы стал более значимым. В современном ЭЖД есть возможность прикрепления домашнего задания. Оказалось, что для девочек важнее, чем для мальчиков, иметь возможность получения ДЗ и прикрепление файлов через электронный дневник.

Основная масса опрошенных не видит особых минусов в ЭЖД. Многие ученики сталкиваются с трудностями подключения к Интернету, дневники часто виснут. В учебное время в них войти практически невозможно. Также их беспокоят ошибки при вводе информации, которые не убираются, для этого нужна либо помощь системных программистов, либо приходится обходить недостатки системы иными способами.

Наиболее актуальным вопрос веса портфелей стал для 8-9классников, потому что именно у них мало сдвоенных уроков, а нагрузка максимально приближенна к нагрузке старшей школы. Для 5-7 классов существенный минус - то, что оценки сразу могут видеть родители. Ученики старше 8-го класса на такие мелочи внимания уже не обращают. 
Электронные учебники. Следующим шагом в цифровой модернизации общеобразовательных учреждений стало оснащение школ электронными учебниками (ЭУ) и цифровыми досками (ЦД). Одним школам в 2018 г. закупили ЭУ (6 школ), другим - ЦД (около 50 школ). Поэтому следующий опрос был про электронные учебники. В анкете «Электронный учебник» было 11 вопросов.

Результаты обследования. Прежде всего, были заданы вопросы: «Как вы относитесь к электронным учебникам?» и «Нужно ли заменить учебники электронными книгами или электронными учебниками?» Отношение детей к электронным учебникам в целом позитивное. Интерес представляет тот факт, что при положительной оценке ЭУ «в принципе» порядка $67 \%$ мальчиков, только $29 \%$ дают однозначный ответ «да» на замену бумажных учебников на электронные. У девочек связка «отношение к ЭУ - отношение к замене» более выраженная, т.е. при 50\% девочек, положительно относящихся к ЭУ, готовы на замену 37\%. Наиболее положительно оценивают новшество 5-классники, наиболее скептически настроены 8-9-классники. При этом, как бы лично каждый не относился к такой замене, они считают, что все-таки заменять бумажные учебники надо.

«Пользуетесь ли Вы электронным учебником/электронной книгой?» Только порядка $60 \%$ используют их в процессе обучения. Причем, речь здесь идет именно об индивидуальном использовании, т.к. классы лицея гаджетами пока не оснащены. Марки стандартные, чаще других — Samsung.

Один из самых важных вопросов для оценки адаптированности школы к цифровизации: «Какие книги вы предпочитаете больше: электронные, бумажные, в зависимости от предмета или ситуации, оба варианта?» Большинство учащихся пока предпочитает бумажный вариант учебников или оба: $27 \%+34 \%$ - мальчики, $38 \%+25 \%$ - девочки. Любопытно, что 5-7-классники вообще игнорируют электронные учебники.

«С какой ступени образования ученики могут активно пользоваться электронными учебниками?» Здесь уже проявляется гендерное расхождение. Большинство мальчиков считает, что с 5 класса, оставляя на начальную школу и старшую по 20-27 \%. Более половины девочек считают, что со старшей школы. И среди них наиболее высока склонность ориентироваться на предмет или ситуацию. Учащиеся средней школы готовы идти в ногу со временем, а вот девочки 8-11 классов считают, что вводить ЭУ надо только со старшей школы. 
«Как респонденты оценили пользу и вред электронных учебников?» Почти никто не считает электронные учебники вредными (только $12 \%$ ). НО! $38 \%$ мальчиков считает, что они точно полезны, тогда как среди девочек такого мнения придерживаются только 6\%, а 64\% считают «50 на 50». Среди 8-9-классников все-таки нашлись люди, считающие ЭУ вредными. Вообще, среди 8-9 классов (по математике и физике они считаются лучшими олимпиадными классами школы) настрой наиболее пессимистичный.

«Каким будет место электронных учебников в ближайшем будущем?» $50 \%$ считает, что электронные учебники в будущем займут свою нишу, порядка 40\% - вытеснят бумажные. Однако, среди девочек нашлись и те, кто считает, что ЭУ не приживутся.

«Каким должен быть электронный учебник в школе? Это должна быть просто электронная книга (аналог бумажного учебника) или это будет собственная полноценная система с 3D-графикой, видео, перекрестными ссылками, связью с Интернетом и т.п.?» Мнения детей разделились 50 на 50, и только два человека из 9-х классов считает, что их вообще не должно быть в школе.

«По каким предметам и циклам прежде всего будут полезны ЭУ?» Мнения разделились почти поровну. Мальчики чуть больше за предметы естественно-научного цикла (ЕНЦ: математика, физика, химия, биология, география), девочки - за предметы гуманитарного цикла (ГЦ). Лидеры в циклах - биология и география в ЕНЦ, литература с историей в ГЦ.

Как респонденты оценивают плюсы и минусы повсеместного введения электронных учебников в школах? Большинство учащихся видит плюсы ЭУ прежде всего в уменьшении веса портфеля (25\% мальчиков, $68 \%$ девочек, 50\% учителей). Многие мальчики давали абстрактный ответ «удобно», девочки наоборот были более конкретны. Среди минусов, девочки чаще мальчиков отмечали нагрузку на глаза и вред для здоровья - $37 \%$ против $25 \%$ у мальчиков. Наиболее актуальным стало уменьшение веса портфеля и ускорение сборов в школу для 5-7 классов.

Никаких минусов в ЭУ не видят, в основном, 11-классники. Наиболее суровы ребята из 8-9 классов. Часть учеников озабочены дороговизной ЭУ и их зависимостью от доступа в Интернет. 
Цифровые доски (ЦД). В 2018 г. лицей оснастили ЦД. В рамках анкетирования «Цифровая доска» были заданы 4 вопроса.

Результаты обследования. "Нужно ли оснащать цифровыми досками все классы или только по отдельным предметам?» Большинство респондентов считает, что все классы. Но, если среди мальчиков так считают почти все (более $80 \%$ ), то среди девочек четверть считает, что по только отдельным предметам.

«Нужно ли оснащать классы цифровыми досками или достаточно экрана или панели с подключением к ПК?» Большинство детей $(79 \%$ мальчиков и $69 \%$ девочек) считает, что ЦД лучше.

«Какие плюсы и минусы существуют у цифровых досок?» Плюсы ученики видят в красочности рисунков, больших возможностях для применения интерактивных технологий обучения, включения видеофрагментов. Для мальчиков 10-11 классов почему-то актуально отсутствие мела при введении цифровых досок. Девочки, наоборот, считают, что доска с мелом (маркерами) в любом случае в классе должна быть, чтобы можно было параллельно делать какие-то пояснения, недоступные для реализации на ЦД.

Старшеклассники особых минусов не видят, 5-7-классники считают, что их здоровье ухудшится. Среди 11 класса были ребята, которые конкретно писали, что от многоцветной доски у них начинают болеть глаза и голова. Беспокоит их также качество соединения с Интернетом.

Ну и, наконец, главный вопрос. Повлияет ли цифровизация на качество образовательного процесса? 37\% мальчиков считает, что существенно улучшит, $38 \%$ что незначительно улучшит. У девочек - $25 \%$ и $19 \%$. Наиболее оптимистичны ученики 5-7 классов. Наиболее пессимистичны ученики 8 класса.

Отдельно был задан вопрос: «Какие еще цифровые функции Вы хотели бы видеть в школе?». Ученики давали следующие варианты ответов: оснащение рабочих мест цифровым оборудованием в кабинетах физики, астрономии, химии, биологии; возможность лекции сразу заносить в планшет; распространение устройств, увеличивающих свободное время и учеников, и учителей; виртуальные очки, виртуальная реальность; плазма с PSU; широкие возможности обработки ДЗ; видеоролики с темами пройденных уроков; подробная информация из дополнительных источников, подобранная по темам уроков; аудио и видеоматериалы (книги, фильмы); больше интерактивных приложений. 
Выводы. Наиболее серьезный вопрос в опросе, который может повлиять на решение администрации школы о закупке электронных носителей — плюсы и минусы электронных учебников. Среди плюсов респонденты отмечали: новшество, инновационность, уменьшение веса портфелей - в одном ЭУ закачены все учебники; зрелищность — игры, 3D-графики, видео и т.п.; возможность прохождения тестирования онлайн и отправки результатов педагогу, а оценок - родителям; лучшая мотивация к обучению для некоторых учеников. В качестве минусов отмечалось: отрицательное влияние на здоровье детей, особенно на зрение; забыл планшет — забыл все учебники; ЭУ связан с подзарядкой, качеством Интернета; ЭУ может стать предметом воровства, нападения после школы; дороговизна (ее отметили даже 5-классники); возможность играть на уроках, отвлекаться; электронный носитель требует бережного отношения. Минусов во введение цифровых досок не видит почти никто, но девочки признают необходимость наличия в классе еще и классической доски.

Вторым таким же важным вопросом является вопрос о том, какие еще цифровые функции учащиеся хотели бы видеть в школе в рамках проекта МЭШ. Их можно сгруппировать по нескольким направлениям:

1) Оснащенность классов оборудованием - оснащение рабочих мест в кабинетах физики, астрономии, химии, биологии (т.е. ЕНЦ).

2) Средства, повышающие интерактивность - виртуальные очки, виртуальная реальность, видеоролики с темами уроков, плазма с PSU, аудио- и видеоматериалы (книги, фильмы) и т.п.

3) Техническое усовершенствование - возможность не писать лекции в тетрадях, а сразу заносить в планшет, более широкие возможности обработки ДЗ - получение, выполнение, отправка, обработка результатов и т.д., облегчение ввода и получения информации, устройства, увеличивающие свободное время, и т.п.

4) Методическая - подробная информация из дополнительных источников, подобранная по темам уроков, большее количество и качественная проработка готовых сценариев уроков, уроки от лучших педагогов страны.

Принципиальных гендерных отличий в ответах на большинство вопросов не выявлено. Поэтому вопрос внедрения электронных средств в школы - это, скорее, вопрос технологического совершенства, инфраструктуры, внимательного отношения к здоровью детей, методологического сопровождения. 


\section{СПИСОК ЛИТЕРАТУРЫ}

1. Бобкова И.А. Электронная школа как составляющая цифровой экономики // Анализ и моделирование экономических и социальных процессов / Математика. Компьютер. Образование: Сб. научн. трудов. Выпуск 25. - М.Ижевск: НИЦ «Регулярная и хаотическая динамика», 2018. с.79-87.

2. Постановление № 1632-р об утверждении программы «Цифровая экономика Российской Федерации» от 28.07.2017.

3. Основные направления в школьном образовании на 2018 год. URL: http://2018god.net/novosti—obrazovaniya-2017-2018—goda.

4. Положение о конкурсе «Информационная образовательная среда нашей школы» URL: http://pandia.ru/text/77/203/76710.php.

5. Образовательные финансы в 2019 году и порядок финансирования школы // Учительская газета Москвы от 26.02.19. URL: http://ug.ru/archive/77953.

6. Более 700 столичных учителей получили гранты за вклад в развитие МЭШ // Москва24 от 15.03.19 URL: https://www.m24.ru/news/gorod/15032019/69195.

\section{SCHOOL DIGITALIZATION:} SCHOOL LIFE IN THE CONDITIONS OF MODERNIZATION

\section{Bobkova I.A.}

Russia has begun an active movement towards a full-fledged digital economy integrated into the global economy. This process is impossible without the involvement of educational institutions (EI). Electronic (digital) school includes technical infrastructure and specialized software, IT implementation in education, preparation of electronic textbooks. The paper analyzes various forms of involving EI in the global digital transformation of the Russian school. 